\title{
Does Interval between Breastfeedıng and Heel Lance Affect the Perception of Pain in Newborns?
}

\author{
Nilgun Altuntas ${ }^{1}$, Serra Altuntas ${ }^{2}$, Dursun $\mathrm{Nar}^{3}$, Meltem Simsek ${ }^{1}$, Ayse Unsal ${ }^{1}$ and Ayse Aybike Gungor ${ }^{3}$ \\ ${ }^{1}$ Department of Pediatrics, Division of Neonatology, Ankara Ylldırım Beyazıt University Medical Faculty, Yenimahalle Training and \\ Research Hospital, Ankara, Turkey \\ ${ }^{2}$ Yuksek Ihtisas University Medical Faculty, Ankara, Turkey \\ ${ }^{3}$ Ankara Yildirim Beyazit University Medical Faculty, Ankara, Turkey
}

\begin{abstract}
Objective: To investigate whether the duration between breastfeeding and heel lance has an effect on babies' pain perception.

Study Design: A randomised trial.

Place and Duration of Study: Obstetrics \& Gynecology Unit, Yenimahalle Training and Research Hospital, Ankara, Turkey between August 2019 and February 2020.

Methodology: Healthy term newborns who were scheduled for a heel lance blood collection for newborn screening were included in the study. Healthy term babies were randomised into three groups, according to their heel lance time. The procedure was performed immediately after breastfeeding (group 1), one hour after breastfeeding (group 2), and two hours after breastfeeding (group 3). The magnitude of pain was measured by the neonatal pain, agitation and sedation scale (N-PASS) one minute before intervention, at the time of intervention, and at 1, 2 and 5 minutes after the intervention. Total crying times of the babies was recorded as well.

Results: Ninety-one babies were included in the study. The pain scores during heel lance and one and two minutes after heel lance were significantly higher in group 3 than in group 1 and group 2. Total crying time of the babies in group 3 was also significantly longer than the total crying time of the babies in group 1 and group 2. However, there was no significant difference between group 1 and 2 in terms of pain scores.

Conclusion: The duration between breastfeeding and heel lance may influence the perception of pain in newborns. Keeping this period short, may reduce the perception of pain.
\end{abstract}

Key Words: Breastfeeding, Breast milk, Newborn, Pain.

How to cite this article: Altuntas N, Altuntas S, Nar D, Simsek M, Unsal A, Gungor AA. Does Interval between Breastfeedıng and Heel Lance Affect the Perception of Pain in Newborns?. J Coll Physicians Surg Pak 2022; 32(01):46-50.

\section{INTRODUCTION}

Pain, which is sometimes a warning sign for the clinician about the presence of a pathological condition, is always an unpleasant and undesirable feeling for the patient. Unfortunately, many interventions applied in intensive care units cause babies to feel this unwanted, stressful feeling. With the demonstrations that pain has permanent consequences, ${ }^{1}$ today great emphasis is placed on the awareness, control and treatment of pain in newborns. Therefore, studies have focused on developing painfree, effective, reliable and easily applicable interventions. To date, many non-pharmacological methods have been shown to reduce the amount of pain and stress when the infant is faced with a painful intervention. ${ }^{2-6}$

Correspondence to: Dr. Nilgun Altuntas, Department of Pediatrics, Division of Neonatology, Ankara Yildirim Beyazit University Medical Faculty, Yenimahalle Training and Research Hospital Ankara, Turkey

E-mail: nilgunaltuntas@hotmail.com

Received: February 14, 2021; Revised: October 11, 2021; Accepted: November 15, 2021

DOI: https://doi.org/10.29271/jcpsp.2022.01.46
Among these, the most physiological non-pharmacological method for pain control during mild and moderate painful interventions in newborns is breastfeeding; hence, the positive effect of breastfeeding on pain response was demonstrated. ${ }^{5-7}$ Breastfeeding has components such as skin-to-skin contact, sucking, odour, the taste of breast milk; and it is considered, each of these have an effect on pain control. ${ }^{5}$ In the situations where mother is unable or unwilling to breastfeed the baby, it was thought that the best alternative to breastfeeding would be donor human milk, but studies have found conflicting results regarding the analgesic effectiveness of breast milk. ${ }^{6-10}$

The pain-reducing effect of breast milk was observed only at high dosesand increased in repeated doses. ${ }^{9 \cdot 11}$ The hindmilk with high fat content was found to be more effective in pain management. ${ }^{11}$ To date, the satiety status of infants has not been mentioned in the studies examining the effectiveness of non-pharmacological pain management in neonates. The state of satiety may also affect the perception of pain.

This study was designed to investigate whether the duration between breastfeeding and painful intervention (heel lance) has an effect on babies' pain perception. To the authors' knowledge, this study is the first study on this subject in the literature. 


\section{METHODOLOGY}

This randomised study was conducted in the Obstetrics \& Gynecology Unit, Yenimahalle Training and Research Hospital, between August 2019 and February 2020. Healthy, full-term and breastfed newborns aged 1-3 days, who needed a heel lance blood collection for neonatal screening, were included in the study. Neonates with diseases that affect breastfeeding, such as congenital anomalies, neurological disorders, cardiac and respiratory disorders, perinatal asphyxia, circulatory disorders, indirect hyperbilirubinemia (IHB) requiring phototherapy, and those with pathological weight losses ( $>7 \%$ weight loss in the first three days), and those whose parents did not provide consent for the study, were excluded from the study. By using Instat-2 statistical software, it was determined that 30 babies would be required in each group in order to achieve the $90 \%$ power necessary to showa $25 \%$ reduction in crying time.

The study was approved by local Ethics Committee. Informed consent was obtained from the legal guardian of each child before enrollment. Before initiating the study, nurses who were involved in data collection, underwent training on the use of $\mathrm{N}$ PASS. The nurses were blinded to the purpose of the study. Only researcher \# 1 (R1) knew that babies would be randomised into three groups, and the randomisation was done by this researcher. Consecutive numbers were assigned to the patients on their enrollment. The numbers were randomly assigned to the study groups in balanced blocks of 10 by using a random allocation software programme, and the babies were divided into three groups; and were breastfed before randomisation. Babies who received sufficient milk measured and determined with test scales were included in the study. For the test scale, the babies were first weighed on an electronic scale, and then breastfed by their mothers for 40 minutes. After breastfeeding, the babies were weighed again with the same dresses, and each gram taken showed the intake of 1cc breast milk. The expected milk volume that infants should take for each feeding session within 3-hour intervals was calculated according to the post-natal age and weight $(60 \mathrm{~mL} / \mathrm{Kg}$ for the first post-natal day, increased by 10 $\mathrm{mL} / \mathrm{Kg}$ for each day). The babies, who had gotten enough breast milk per meal, were randomised into three groups by R1. The procedure was applied immediately (group 1 ), at the 1st hour (group 2) and at the 2nd hour (group 3) after breastfeeding. Babies were sent to the intervention room by R1. Demographic features of the babies were recorded by R1. The researchers in the intervention room were not informed about the feeding time of the babies. Before the intervention, the babies were laid on the open bed and a pulse oximeter was attached to their right wrists. They were clothed and the procedure was performed at room temperature. R2 performed the intervention (heel lance), R3 recorded the vital signs, and $\mathrm{R} 4$ gave the pain scores. Pain scoring was performed one minute before, at the time of heel lance and 1,2 and 5 minutes after the intervention. Oxygen saturations and heart peak beats were observed with a pulse oximeter. The duration of procedure and total crying time of the babies were recorded by R5.
The neonatal pain, agitation, and sedation scale (N-PASS) was developed as a clinically relevant tool to assess prolonged pain and sedation in preterm and term infants, as well as acute-procedural pain. ${ }^{12}$ The 'pain/agitation' assessment portion of the NPASS was used in this study. Validity and reliability of the N-PASS with prolonged pain has been described. ${ }^{13}$ The validity and reliability of the N-PASS tool with acute-procedural pain, specifically, heel prick blood collection was demonstrated later. ${ }^{14}$ The five indicators are (1) crying, (2) behaviour/state, (3) facial expression, (4) extremities/tone, and (5) vital signs. The scores for each criterion ranged from 0 to 2 , total scores range from 0 to 10. Total pain score of 0 would indicate "no pain", four points and below reflects mild pain, five points and above reflects moderate and severe pain for the N-PASS.

Crying time and duration of the first cry was revealed to be a sensitive method for assessment of pain and analgesia in the literature. ${ }^{15,16}$ Crying was noted as audible vocalisation that lasted at least $5 \mathrm{~s}$ without a 20 s quiet interval. Total crying time was defined as the duration of crying during procedure.

All analyses were performed with a commercially available software programme (Statistical Package for the Social Sciences, version 25, SPSS Inc., Chicago, IL, USA). Normality of data was analysed with Shapiro-Wilk test and the normally distributed variables were expressed as means (standard deviations); and the non-normally distributed variables were expressed as medians (IQR: 25th percentile-75th percentile). Chi-square test was used for categorical variables and expressed as observation counts (in percentages). One-way ANOVA test was used for parametric data and Kruskal-Wallis test was used for non-parametric data in comparison of the three groups. When a significant difference was detected in the N-PASS scores, the origin of the difference was investigated by 'Dunn-Bonferroni post hoc' test. A two-sided $p$-value $<0.05$ was considered as statistically significant.

\section{RESULTS}

In a 7-month period, 130 babies were included in the study. Thirty-nine babies were excluded. Of those, 20 babies did not receive sufficient volume of breast milk and nine babies remained restless despite feeding. Remaining 10 babies were sleeping at the time of the procedure. As a result, 91 babies with sufficient feeding and calm alertness were included in the study; and were randomised into three groups. Heel lance was applied immediately after breastfeeding (group, $n=31$ ), one hour after breastfeeding (group $2, n=30$ ) and two hours after breastfeeding (group $3, n=30$ ). The demographic characteristics of the babies are given in Table I. There was no statistically significant difference between the groups in terms of gestational week $(p=0.585)$, birth weight $(p=0.737)$, post-natal age $(p=0.189)$, gender $(p=0.417$, mode of delivery $(p=0.441$, and duration of the procedure $(p=0.822)$. There was no any statistically significant difference between the groups in terms of their pain scores before $(p=0.601)$, and at the 5 th minute $(p=0.068)$ after the procedure. 
Table I: Demographic and clinical characteristics of the study population.

\begin{tabular}{|c|c|c|c|c|}
\hline & $\begin{array}{c}\text { Group } 1 \\
\mathrm{n}: 31\end{array}$ & $\begin{array}{c}\text { Group } 2 \\
\mathrm{n}: 30\end{array}$ & $\begin{array}{c}\text { Group } 3 \\
\text { n: } 30\end{array}$ & $\mathbf{p}$ \\
\hline Gestational age (week) $^{a}$ & $38(38-39)$ & $39(38-39)$ & $38.5(38-40)$ & $0.585^{\mathrm{K}}$ \\
\hline Birth weight (gram) ${ }^{b}$ & $3330 \pm 386.90$ & $3371.5 \pm 421.03$ & $3414 \pm 449.46$ & $0.737^{A}$ \\
\hline $\begin{array}{l}\text { Gender, n (\%) } \\
\text { Female } \\
\text { Male }\end{array}$ & $\begin{array}{l}12(38.7) \\
19(61.3)\end{array}$ & $\begin{array}{l}16(53.3) \\
14(46.7)\end{array}$ & $\begin{array}{l}16(53.3) \\
14(46.7)\end{array}$ & $0.417^{\mathrm{P}}$ \\
\hline $\begin{array}{l}\text { Type of delivery, } \mathrm{n}(\%) \\
\text { NVD } \\
\text { C/S }\end{array}$ & $\begin{array}{l}16(51.6) \\
15(48.4)\end{array}$ & $\begin{array}{l}11(36.7) \\
19(63.3)\end{array}$ & $\begin{array}{l}15(50) \\
15(50)\end{array}$ & $0.441^{P}$ \\
\hline Postnatal age (hour) & $25(24-36)$ & $24(24-24.25)$ & $24(23.75-26)$ & $0.189^{K}$ \\
\hline $\begin{array}{l}\text { Duration of procedure } \\
\text { (second) }{ }^{a}\end{array}$ & $69(55-120)$ & $74.5(52.75-93.25)$ & $71.5(64-95.75)$ & $0.82^{\mathrm{K}}$ \\
\hline
\end{tabular}

Table II: NPAS scores of groups.

\begin{tabular}{|c|c|c|c|c|c|c|c|c|c|c|c|c|c|c|c|c|c|}
\hline \multirow{3}{*}{$\begin{array}{l}\text { Before } \\
\text { prick }\end{array}$} & \multirow[b]{2}{*}{ Mean. \pm SD } & \multicolumn{4}{|c|}{$\begin{array}{c}\text { Group } 1 \\
\text { n: } 31\end{array}$} & \multicolumn{4}{|c|}{$\begin{array}{c}\text { Group II } \\
\text { n: } \mathbf{3 0}\end{array}$} & \multicolumn{4}{|c|}{$\begin{array}{c}\text { Group III } \\
\text { n: } \mathbf{3 0}\end{array}$} & \multirow{3}{*}{$\begin{array}{c}\mathbf{p} \\
0.601\end{array}$} & \multirow{3}{*}{\begin{tabular}{|c|} 
Group \\
1 vs. 2 \\
$(-)$
\end{tabular}} & \multirow{3}{*}{$\begin{array}{c}\begin{array}{c}\text { Group } \\
2 \text { vs. } 3\end{array} \\
(-)\end{array}$} & \multirow{3}{*}{$\begin{array}{c}\begin{array}{c}\text { Group } \\
1 \text { vs. } 3\end{array} \\
(-)\end{array}$} \\
\hline & & & 0.29 & \pm & 0.93 & & 0.10 & \pm & 0.54 & & 0.10 & \pm & 0.40 & & & & \\
\hline & Med (IQR:25-75) & 0 & 0 & - & 0 & 0 & 0 & - & 0 & 0 & 0 & - & 0 & & & & \\
\hline \multirow{2}{*}{$\begin{array}{l}\text { Prick } \\
\text { moment }\end{array}$} & Mean. \pm SD & & 3.90 & \pm & 2.85 & & 4.66 & \pm & 2.03 & & 8.13 & \pm & 1.96 & \multirow{2}{*}{$<0.001$} & \multirow{2}{*}{$>0.999$} & \multirow{2}{*}{$<0.001 *$} & \multirow{2}{*}{$<0.001^{*}$} \\
\hline & Med (IQR:25-75) & 4 & 2.0 & - & 6.0 & 5 & 3.75 & - & 6.0 & 8 & 7 & - & 10 & & & & \\
\hline \multirow{2}{*}{$\begin{array}{l}\text { 1st } \\
\text { minute }\end{array}$} & Mean. \pm SD & & 0.70 & \pm & 1.55 & & 1.06 & \pm & 1.52 & & 4.03 & \pm & 2.39 & \multirow{2}{*}{$<0.001$} & \multirow{2}{*}{$>0.999$} & \multirow{2}{*}{$<0.001^{*}$} & \multirow{2}{*}{$<0.001^{*}$} \\
\hline & Med (IQR:25-75) & 0 & 0 & - & 0 & 0 & 0 & - & 2.25 & 5 & 3 & - & 5.25 & & & & \\
\hline \multirow{2}{*}{$\begin{array}{l}\text { 2nd } \\
\text { minute }\end{array}$} & Mean. \pm SD & & 0.25 & \pm & 1.12 & & 0.13 & \pm & 0.50 & & 1.70 & \pm & 1.95 & \multirow{2}{*}{$<0.001$} & \multirow{2}{*}{$>0.999$} & \multirow{2}{*}{$<0.001 *$} & \multirow{2}{*}{$<0.001 *$} \\
\hline & Med (IQR:25-75) & 0 & 0 & - & 0 & 0 & 0 & - & 0 & 1 & 0 & - & 3 & & & & \\
\hline \multirow{2}{*}{$\begin{array}{l}5 \text { th } \\
\text { minute }\end{array}$} & Mean $\pm S D$ & & 0.22 & \pm & 1.25 & & 0 & \pm & 0 & & 0.40 & \pm & 1.19 & \multirow{2}{*}{0.068} & \multirow{2}{*}{$(-)$} & \multirow{2}{*}{$(-)$} & \multirow{2}{*}{$(-)$} \\
\hline & Med (IQR:25-75) & 0 & 0 & - & 0 & 0 & 0 & - & 0 & 0 & 0 & - & 0 & & & & \\
\hline \multirow{2}{*}{$\begin{array}{l}\text { Total } \\
\text { Craying } \\
\text { time }\end{array}$} & Mean. \pm SD & & 64.10 & \pm & 74.20 & & 81.60 & \pm & 40.66 & & 126.50 & \pm & 60.15 & \multirow{2}{*}{$<0.001$} & \multirow{2}{*}{0.106} & \multirow{2}{*}{0.027} & \multirow{2}{*}{$<0.001^{*}$} \\
\hline & Med (IQR:25-75) & 38 & 10 & - & 67 & 79 & 50.25 & - & 110.75 & 114 & 93.5 & - & 151.25 & & & & \\
\hline
\end{tabular}

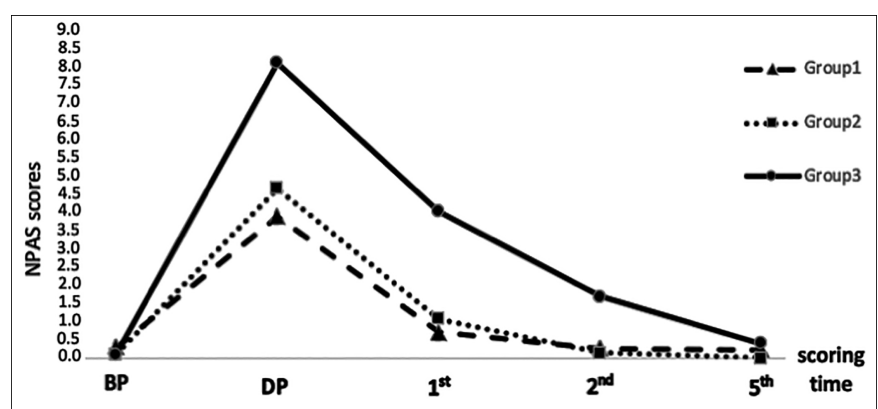

Figure 1: NPAS scores of groups. DP: During prick, PM:Prick moment, 1'st min: 1 minute after prick, 2'nd min: 2 minute after prick, 5'th min: 5 minute after prick.

The pain scores of the babies in group 3 at the time of heel lance blood collection and one and two minutes after the intervention were significantly higher than the pain scores of the babies in group 2 and group 1 ( $p<0.001$, Figure 1$)$. Total crying time of the babies in group 3 was also longer than the total crying time of the babies in group $1(p<0.001)$ and group $2(p=0.027)$. However, there was no significant difference between group 1 and 2 in terms of N-PASS scores and total crying time $(p>0.05)$. N-PASS scores and crying times of the babies in three groups are given in Table II.

\section{DISCUSSION}

In this study, it was found that the prolonged time between breastfeeding and heel lance was accompanied by an increase in pain scores and total crying time. According to these results, keeping the time between breastfeeding and the intervention short may be more effective in pain control.

The pain-reducing effect of breastfeeding has been shown in many studies before. ${ }^{5-7,17,18}$ However, in these studies, breastfeeding was performed during the painful intervention; and the duration of effectiveness of breastfeeding on pain control has not been studied, yet. In studies evaluating pain relief provided by receiving small volumes of sucrose or glucose or breast-feeding; the sugar solutions or breast milk were usually given two minutes before the painful procedure; and in some, the doses were repeated throughout the

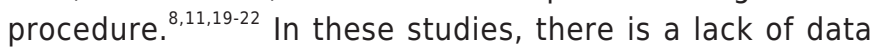
about the length of feeding and the time interval between feeding and painful intervention. In the study evaluating the analgesic effect of $2 \mathrm{ml}$ of $25 \%$ sucrose and human milk in a group of healthy term newborns, the babies were fed at least one hour beforehand the heel prick blood sampling. Neither the reason for the preference of feeding time nor 
avarage length of feeding time was mentioned by the authors. In another study, evaluating the analgesic effect of breastfeeding, ${ }^{17}$ the participants were the babies who were breastfed (intervention group) or swaddled in the bassinets (control group) during heel lance. All infants were breastfed 30 minutes to four hours before the procedure. Breastfeeding was found to be a potent analgesic intervention in newborns during a standard blood collection. The authors did not mention the possible effect of the duration between breastfeeding and the painful intervention on pain perception. However, they stated that there was no significant difference between the groups in terms of mean feeding times.

The design of this study is different from the others. No painreducing intervention, such as breastfeeding, sucrose or pacifier, was utilised during the painful procedure. Thus, it was only tested whether the duration between breastfeeding and painful intervention affects the perception of pain. To authors' knowledge, there is no similar study in the literature. Therefore, the authors could not compare these results in this respect.

It has some limitations, too. Feeding was only provided by breastfeeding in babies included in the study and randomisation was made according to the duration of time between feeding and the painful procedure. According to these results, it is suggested that shortening this period may reduce the perception of pain. However, it is not possible to distinguish whether this positive effect is due to breastfeeding or the state of satiety. If formula and breast milk fed groups were compared in this study, one might have reached a clearer conclusion on this issue. However, considering the negative effect of feeding with formula on breastfeeding in the early days of life, such a study would not be ethical.

\section{CONCLUSION}

Breastfeeding of the baby and short duration between breastfeeding and painful procedure may reduce the baby's perception of pain during the intervention.

\section{ETHICAL APPROVAL:}

The study was approved by local Ethics Committee (Ankara Yıldırım Beyazıt University, Yenimahalle Training and Research Hospital Ethical Committee).

\section{PATIENTS' CONSENT:}

Informed consent was obtained from the legal guardian of each child before enrollment.

\section{CONFLICT OF INTEREST:}

The authors declared no conflict of interest.

\section{AUTHORS' CONTRIBUTION:}

NA: Study design, supervision, manuscript writing, analysis. SA: Data collection, manuscript writing.
DN, AU: Data collection, analysis.

MS, AAG: Data collection.

\section{REFERENCES}

1. Anand KJ, Scalzo FM. Can adverse neonatal experiences alter brain development and subsequent behavior? Biol Neonate 2000; 77(2):69-82. doi: 10.1159/000014197.

2. Pillai Riddell RR, Racine NM, Gennis HG, Turcotte $K$, Uman LS, Horton RE, et al. Non-pharmacological management of infant and young child procedural pain. Cochrane Database Syst Rev 2015; 2015(12):CD0062752. doi: 10.1002/ 14651858.CD006275.pub3.

3. Akcam M. Oral fructose solution as an analgesic in the newborn: A randomised, placebo-controlled and masked study. Pediatr Int 2004; 46(4):459-62. doi: 10.1111/j.1442200x.2004.01932.x.

4. Mc Nairv C, Campbell-Yeo M, Johnston C, Taddio A. Nonpharmacologic management of pain during commen needle puncture procedures in Infants: Current research evidence and practical considerations: An update. Clin Perinatol 2019; 46(4):709-30. doi: 10.1016/j.clp.2019.08.006.

5. Leite AM, Linhares MB, Lander J, Castral TC, Santos CB, Silvan Scochi CG. Effects on breastfeeding on pain relief in full-term newborns. Clin J Pain 2009; 25(9):827-32. doi: 10.1097/AJP.0b013e3181b51191.

6. Shah PS, Herbozo C, Aliwalas LL, Shah VS. Breastfeeding or breastmilk for procedural pain in neonates. Cochrane Database Syst Rev 2012; 12:CD004950.

7. Analgesia in Benoit $B$, Martin-Misener R, Latimer M, Marsha Campbell-Yeo. Breast-feeding analgesia in infants: An update on the current state of evidence. J Perinat Neonatal Nurs 2017; 31(2):145-59. doi: 10.1097/JPN.0000000000 000253.

8. Skogsdal Y, Eriksson M, Schollin J. Analgesia in newborns given oral glucose. Acta Paediatr 1997; 86(2):217-220. doi: 10.1111/j.1651-2227.1997.tb08872.x.

9. Ors R, Ozek E, Baysoy G, Cebeci D, Bilgen H, Turkuner M, et al. Comparison of sucrose and human milk on pain response in newborns. Eur J Pediatr 1999; 158(1):63-6. doi: 10.1007/s004310051011..

10. Upadhyay A, Aggarwal R, Narayan S, Joshi M, Paul VK, Deorari AK. Analgesic effect of breastmilk in procedural pain in term neonates: A randomised, placebo-controlled, double-blind trial. Acta Paediatr 2004; 93(4):518-22. doi: 10.1080/08035250410022792.

11. Altun-Koroglu O, Ozek E, Bilgen $H$, cebeci D. Hindmilk for procedural pain in term neonates. Turk J Pediatr 2010; 52(6):623-9.

12. Hummel P, Puchalski M, , Weiss MG, Creech SD. Neonatal pain, agitation and sedation scale - reliability and validity. Poster presented at; the Pediatric Academic Societies annual meeting; May 3-6, 2003; Seattle, WA.

13. Hummel P, Puchalski M, Creech SD, Weiss MG. Clinical reliability and validity of the N-PASS: Neonatal pain, agitation and sedation scale with prolonged pain. J Perinatol 2008; 28(1):55-60. doi: 10.1038/sj.jp.7211861. 
14. Hummel P, Lawlor-Klean P, Weiss MG. Validity and reliability of the N-Pass assessment with acute pain. J Perinatol 2010; 30(7):474-8. doi: 10.1038/jp.2009.185.

15. Grunau RV, Johnston CC, Craig KD. Neonatal facial and cry responses to invasive and non-invasive procedures. Pain 1990; 42(3):295-305. doi: 10.1016/0304-3959(90)91142-6.

16. Grunau RV, Craig KD. Pain expression in neonates: Facial action and cry. Pain 1987; 28(3):395-410. doi: 10.1016/ 0304-3959(87)90073-X.

17. Gray L, Miller LW, Philipp BL, Blass EM. Breastfeeding is analgesic in healty newborns. Pediatrics 2002; 109(4): 590-3. doi: 10.1542/peds.109.4.590.

18. Uga E, Candriella M, Perino A, Alloni V, Angilella G, Trada M, et al. Heel lance in newborn during breastfeeding: An evaluation of analgesic effect of this procedure. Ital J Pediatr
2008; 34(1):3. doi: 10.1186/1824-7288-34-3.

19. Codipietro L, Ceccarelli M, Ponzone A. Breastfeeding or oral sucrose solution in term neonates receiving heel lance: $A$ randomised, controlled trial. Pediatrics 2008; 122(3): e716-21.

20. Akman I, Ozek E, Bilgen H, Ozdogan T, Cebeci D. Sweet solutions and pacifiers for pain relief in newborn infants. J Pain 2002; 3(3):199-202. doi: 10.1054/jpai.2002.122943.

21. Bucher HU, Moser T, von Siebenthal K, Keel M, Wolf M, Duc $G$. Sucrose reduces pain reaction to heel lancing in preterm infants: A placebo controlled, randomised and masked study. Pediatr Res 1995; 38(3):332-5. doi: 10.1203/ 00006450-199509000-00010.

22. Blass EM, Hoffmeyer LB. Sucrose as an anagesic for newborn infant. Pediatrics 1991; 87:215-8. 